\title{
Sobre la figura del campesino y la gestión del territorio: Una aproximación desde Nariño (Colombia)
}

Tyanif Rico Rodríguez y Pedro Sergio Urquijo Torres

\begin{abstract}
PALABRAS CLAVE: campesinos de Colombia, ordenamiento social del territorio, historia agraria, etnografía.
\end{abstract}

\author{
CÓDIGOS JEL: R14, Q24, Q18, Q15.
}

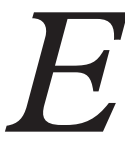

lobjetivo de este texto es mostrar la trayectoria de la noción de campesino en el contexto institucional colombiano, a partir de un análisis desde Nariño (Co-

lombia), para reconocer que sus usos institucionales están atravesados por la necesidad de regular y desarrollar «lo rural» desde la noción misma. Campesino ha sido usada como una categoría de gestión del territorio, entendido como un conjunto de tecnologías, cultivos y poblaciones. Las organizaciones campesinas en Colombia hoy buscan posicionar esta noción como una categoría de ciudadanía efectiva y de ordenamiento social del territorio, más allá de una forma de controlar y administrar la tierra. Para ello, realizamos un estudio descriptivo de la configuración de la figura de campesino, desde el ámbito institucional de cara al contexto de Nariño. Planteamos reflexiones sobre los usos actuales y disputas a través de los marcos institucionales que buscan u omiten su reconocimiento, como categoría agraria y ciudadana. Finalmente, proveemos algunas reflexiones sobre las estrategias para regular los espacios rurales a partir de categorías y políticas territoriales centradas en los sujetos. La importancia de este análisis es la visibilización de las estrategias de las organizaciones comunitarias para construir, desde su trayectoria local, nociones de campesinado centradas en el reconocimiento de la ciudadanía, más allá del carácter funcional y productivo que han tenido a los ojos del Estado. 


\title{
On the figure of "campesino" and the management of the territory: An approach from Nariño, Colombia
}

\author{
KEYWORDS: Colombian peasantry, territorial orderings, agrarian \\ history, ethnography.
}

JEL CODES: R14, Q24, Q18, Q15.

is paper aims to show the trajectory of the "campesino" notion in the Colom-
bian institutional context. "Campesino" has been used as a territorial man-
agement strategy to organize a set of technologies, populations, crops, and soil use. Peasant organizations in Colombia today seek to position this notion as a category of effective citizenship, and social ordering of their territories. To do this, we carried out a descriptive study of the configuration of the figure of the peasant from the institutional level facing the context of Nariño. Methodologically, we used different qualitative research tools to dig in an ethnographic perspective of the agrarian, environmental, and social organization history of the region. We raise some reflections on current uses and disputes through institutional frameworks that seek, or omit, their recognition as an agrarian and citizenship category. Finally, we provide some reflections on the strategies and frameworks to regulate rural spaces based on subject-centered categories and territorial policies. The importance of this analysis is the visibility of the strategies of community organizations to build, from their local experience, notions of peasantry focused on the recognition of citizenship, beyond the functional and productive character posed by the State.

Recepción: 2019-12-11 - Revisión: 2020-06-16 - Aceptación: 2020-06-23

Tyanif Rico Rodríguez [orcid.org/0000-0003-0922-9453] es candidata doctoral en Geografía del Centro de Investigación en Geografía Ambiental (CIGA) de la Universidad Nacional Autónoma de México. Dirección para correspondencia: CIGA, Antigua carretera a Pátzcuaro, 8701, 58190 Morelia (México). C. e.: erico@pmip.unam.mx

Pedro Sergio Urquijo Torres [orcid.org/0000-0001-9626-0322] es investigador titular definitivo en el Centro de Investigaciones en Geografía Ambiental (CIGA) de la Universidad Nacional Autónoma de México. Dirección para correspondencia: CIGA, Antigua carretera a Pátzcuaro, 8701, 58190 Morelia (México).C.e.:psurquijo@ciga.unam.mx 


\section{INTRODUCCIÓN}

En la historia reciente de Colombia, la noción de campesino está estrechamente vinculada a la configuración de los territorios rurales y la transformación de los paisajes. Ello debido a que la historia de formación del Estado nación ha ido aparejada con las luchas sociales, el reclamo por la tierra y sus formas de uso. Entre la literatura que se puede consultar al respecto están los trabajos de Duarte (2015), que representan las investigaciones recientes. Sin embargo, campesino no solamente refiere a un tipo de identificación del sujeto que trabaja el campo, sino a un tipo de relación territorial que incluye una dimensión productiva, pero que no necesariamente se reduce a ella. Esta involucra distintos proyectos institucionales ejecutados discursiva y políticamente para ordenar el territorio y a quienes lo habitan.

La idea de campesino se ha configurado a partir de distintas trayectorias locales e institucionales; por tanto, una mejor comprensión de su construcción discursiva puede arrojar luz sobre formas prospectivas de ordenamiento territorial y ambiental acuciantes para el contexto actual en el campo colombiano. En el marco del posconflicto armado, el conflicto por la tierra ha empezado a reconocerse como un problema estructural de ciudadanía que demanda garantías para la vida y el desarrollo de las personas. La lente del desarrollo económico con la que se ha pensado resolver el problema de rezago rural ha empezado a transformarse. Evidenciar los matices que tienen las políticas y decisiones a nivel nacional, desde el contexto local de una región tradicionalmente campesina y periférica a los proyectos de desarrollo económico nacional, es relevante para entender la complejidad de la construcción de procesos de subjetivación, ciudadanía y organización de la tierra.

La idea de campesino hoy toma relevancia porque desde las organizaciones comunitarias de la región norte de Nariño, las cuales han tenido un papel determinante en el debate y la movilización política, se plantea como un mecanismo para el reconocimiento de la ciudadanía colectiva, agraria y territorial. Una propuesta contraria al uso que se le ha dado institucionalmente a esta categoría, como mecanismo para controlar las zonas rurales, al ser leídas como superficies vacías a las que se les da orden a través de criterios económicos. La búsqueda de las organizaciones comunitarias, actualmente desde la región norte de Nariño, es construir desde una figura de ordenamiento social del territorio una categoría específica de ciudadanía y participación política que permita el reconocimiento efectivo de derechos, y la posibilidad de ejercerlos en términos territoriales.

Nuestro análisis hace una aproximación a los agenciamientos institucionales, para identificar las formas en que esta categoría se ha usado en este contexto. Asimismo, reconoce 
que el uso de esta noción en planes y proyectos de modernización y desarrollo, como marcos que han buscado regular lo rural a partir de decisiones sobre la tierra (como vectores de los ordenamientos del territorio) han sido para denominar a quienes cumplen funciones de trabajo agrícola. Lo anterior suele realizarse desconociendo el amplio panorama de elementos que constituyen una idea de sujeto campesino, cuando se la entiende como una noción de ciudadanía, en la cual primen criterios y nociones territoriales, más allá de su condición de trabajo.

El carácter colectivo y territorial del campesinado se ha estudiado a través de múltiples formas. Algunas han buscado comprender los procesos de subjetivación a partir de las prácticas institucionales en función de las políticas de conservación y la configuración de subjetividades ambientales (Agrawal, 2005). Otros análisis se centran en la producción de conocimiento espacial de las comunidades campesinas y en la forma en como estas prácticas de conocimiento son también prácticas de supervivencia y manejo de recursos naturales, por ejemplo, el bosque (Wartmann \& Purves, 2016). Incluso hay trabajos que buscan comprender cómo se configuran subjetividades territoriales en un proceso mutuo y constante entre seres y lugares (Cadena, 2015; Singh, 2017).

En Colombia, particularmente, el estudio sobre el campesinado ha estado centrado en los procesos de organización y disputa territorial por la ciudadanía y el reconocimiento cultural (Duarte, 2015). Una muestra de esto se encuentra en el marco diferencial de derechos que consigna la Constitución Política de Colombia (CPC) de 1991, como afirman Duarte (2015) y Montaña (2016). Un marco normativo que dio a indígenas y afros herramientas para el ejercicio de sus derechos como ciudadanos y la posibilidad del ejercicio colectivo de sus derechos territoriales. Caso contrario ocurrió con los campesinos también como habitantes de los espacios rurales, a los que se reconoce como trabajadores agrícolas ${ }^{1}$. Este escenario propició que durante mediados de la década de los noventa, en lo que Fajardo (2012) llama la renovación del debate agrario, surgieran espacios para el reclamo territorial de los derechos campesinos a través de las zonas de reserva campesina (ZRC) como primeros pasos para asentar institucionalmente las disputas territoriales en la CPC.

La noción de campesino hoy constituye el eje de las demandas políticas de las organizaciones de base, y de algunos académicos y políticos que se suman a sus peticiones. Entre éstas, destacan el Proyecto de Acto Legislativo 02 de 2018, por medio del cual se reconoce al campesinado como sujeto de derechos, se reconoce el derecho a la tierra y a la te-

1. Como se nombra a los habitantes de las zonas rurales en la Constitución Política de Colombia (1991). 
rritorialidad campesina y se adoptan disposiciones sobre la consulta popular ${ }^{2}$. Se destaca también el papel de los académicos convocados por los requerimientos de las organizaciones sociales a través del Instituto Colombiano de Antropología e Historia (ICANH, 2018) y de los académicos integrantes de la comisión de expertos que acompañaron la construcción del «Pacto por la equidad rural y el bienestar de la población campesina» como propuesta técnica para el actual Plan Nacional de Desarrollo de Colombia propuesto por las organizaciones campesinas de orden nacional y regional (2018). La noción de campesino busca posicionarse a partir de recursos identitarios, producto de distintos discursos y proyectos en múltiples realidades territoriales. De allí la necesidad de pensar de forma situada a partir de la trayectoria de las organizaciones campesinas (en este caso desde la región norte de Nariño) como un espacio de movilización y organización comunitaria.

En la región norte de Nariño (Fig. 1) el papel de la Iglesia ha sido fundamental en asociación con los proyectos de modernización, alfabetización y desarrollo. Su presencia ha contribuido en la configuración de identificaciones productivas y sensibilidades ambientales que se traducen en la capacidad de reconocimiento de conflictos ambientales y territoriales relacionados con los recursos y la naturaleza por parte de quienes habitan esa región.

Uno de los puntos de partida de esta revisión son los proyectos de desarrollo y modernización enmarcados en los esfuerzos de las políticas de tierras, reforma agraria y desarrollo rural que han moldeado de forma periférica o directa ideas de trabajador agrícola, luego campesino, consignadas en la Constitución con usos ambivalentes. En los últimos años el debate en torno al problema agrario ha empezado a vislumbrarse y reconocerse, desde la institucionalidad del Estado, como un problema de ordenamiento social de la propiedad. El Decreto 902 evidencia esta necesidad de titulación como mecanismo para la implementación de los acuerdos de paz. Por el contrario, para las organizaciones campesinas el objetivo es construir una categoría de ciudadanía efectiva desde una perspectiva de ordenamiento territorial y ecológico de la propiedad. Esta podría ser una vía que agencie el reconocimiento de sus derechos colectivos y territoriales, como se busca a través de la propuesta del Territorio Campesino Agroalimentario del Norte de Nariño.

2. Un proyecto de acto legislativo, que fue archivado después del primer debate en el Senado, puede consultarse en: http:/www.comisionprimerasenado.com/proyectos-de-acto-legislativo/4-pormedio-del-cual-se-reconoce-al-campesinado-como-sujeto-de-derechos-se-reconoce-el-derecho-a-latierra-y-a-la-territorialidad-campesina-y-se-adoptan-disposiciones-sobre-la-consulta-popular 


\section{FIGURA 1}

Área de estudio. Ubicación de la región norte de Nariño
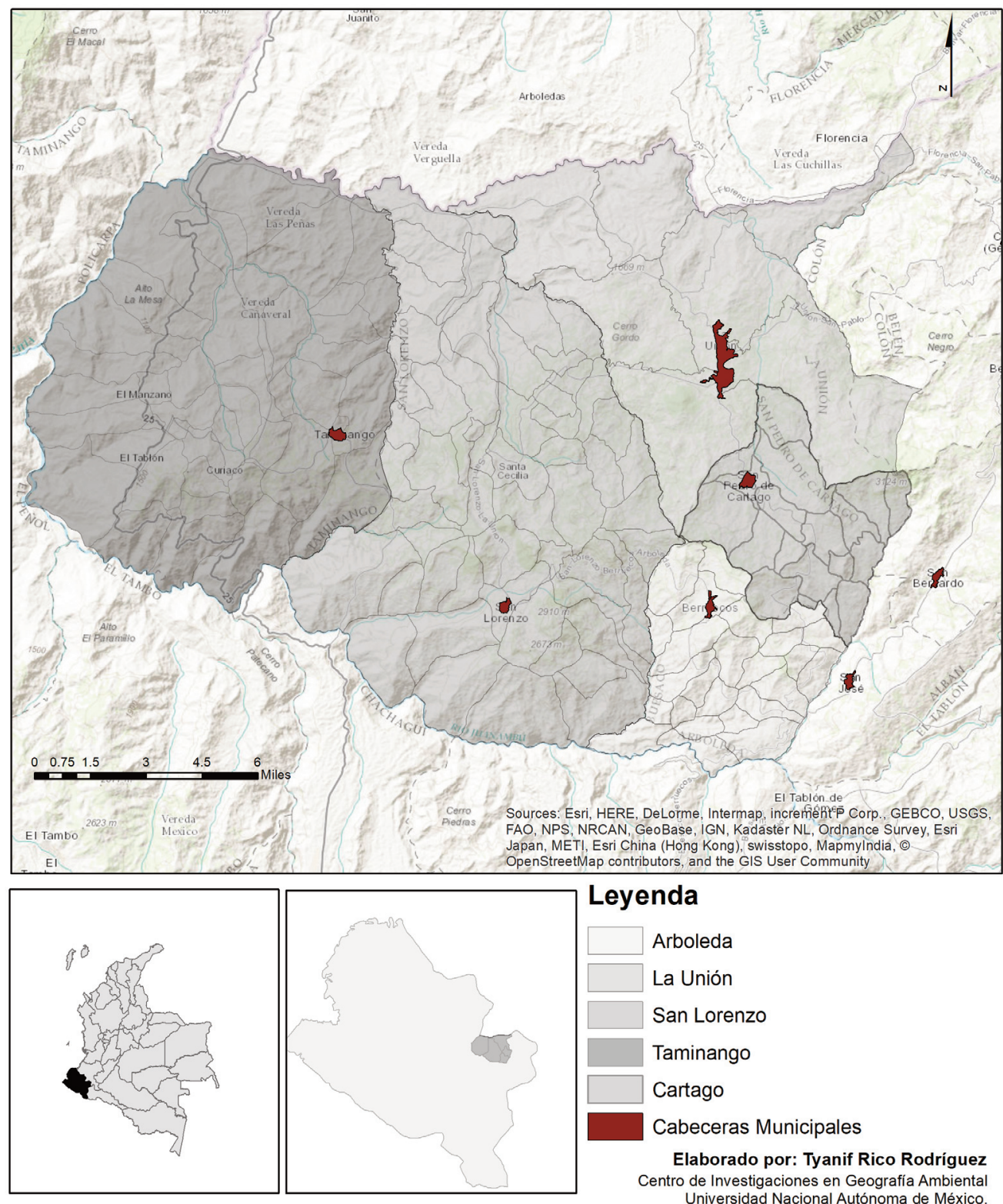

\section{Leyenda}

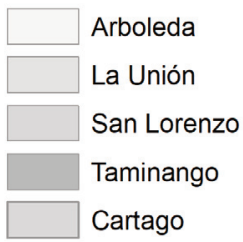

Cabeceras Municipales

Elaborado por: Tyanif Rico Rodríguez

Centro de Investigaciones en Geografía Ambiental Universidad Nacional Autónoma de México.

Fuente: elaboración propia. 


\section{ASPECTOS METODOLÓGICOS}

El análisis expuesto en este documento se construyó a partir de distintos materiales y herramientas cualitativas de investigación que buscaban indagar por la historia agraria y la organización social y productiva del norte de Nariño. Esta recopilación se hizo en distintos periodos de trabajo de campo entre 2015 y 2018. La investigación se basó en una exhaustiva revisión documental y de archivo, la observación de campo y la realización de entrevistas semiestructuradas. La revisión documental se hizo a través del material disponible en la Biblioteca Luis Ángel Arango (BLAA) y la Biblioteca Nacional de Colombia (BNC). En el material revisado se encuentran informes de economía regional, informes de la Federación Nacional de Cafeteros, material sobre los programas sociales de la Iglesia y literatura sobre procesos de poblamiento y distribución de la tierra en la región (Oviedo, 2014). El material de archivo consultado hace parte del acervo de Acción Cultural Popular (ACPO) del repositorio de la BLAA, en donde se revisaron cartas, fotografías, notas de periódico, informes y programas de radio. Sumado a esto se revisó la cartografía histórica disponible en el acervo digital de la misma biblioteca.

Las entrevistas se utilizaron como material oral para marcar momentos clave en la periodización de una historia agraria de la zona. Las preguntas buscaban recabar información sobre los procesos de poblamiento de la región a partir de la trayectoria familiar y de las transformaciones en el uso y propiedad de la tierra. La información recabada permitió analizar las transformaciones agrarias de las que no se tienen datos en ningún archivo disponible para la región. Algunos ejemplos son: los periodos de asentamiento familiar en la zona; el tamaño de las fincas y su división; los sistemas de tenencia y compraventa; o las políticas de reparto agrario, crédito productivo y asistencia técnica. $\mathrm{La}$ muestra se hizo a partir de recorridos en campo guiados por líderes de cada municipio del área de estudio, a través de la estrategia de bola de nieve, con un total de 32 personas (20 hombres y 12 mujeres, entre 35 y 70 años). El objetivo de las entrevistas era indagar por la trayectoria de asentamiento de los campesinos y sus familias, los momentos coyunturales o hitos productivos que marcaron los usos del suelo en función de su trayectoria vital. Algunos de estos campesinos pertenecen a organizaciones comunitarias, otros son líderes tradicionales cuya trayectoria organizativa es reconocida colectivamente y, por ende, referidos como actores centrales para la información buscada en campo sobre la trayectoria de poblamiento y organización social de la región.

De la información recabada en las entrevistas, se identificaron y seleccionaron los eventos clave que los entrevistados señalaban como hitos en su historia, relacionados con luchas agrarias; eventos naturales como la erupción del volcán Doña Juana (Navarro et al., 2009), o la intervención de actores como la Iglesia o la Federación Nacional de Cafeta- 
leros de Colombia (FNCC). Estos eventos se triangularon con la información disponible en los archivos para encontrar un marco temporal que permitiera comprender los procesos agrarios de la región. Así fue como el establecimiento del café en la zona hacia la década de 1930 y su importancia para los procesos de asentamiento y organización permiten explicar el desarrollo de una identidad productiva de los campesinos de la zona. Asimismo, estos eventos clave permitieron identificar cómo los programas, políticas y estrategias institucionales tienen matices locales con resonancia en los espacios de decisión nacional e institucional.

\section{CONTEXTO SOCIOECONÓMICO DE LA REGIÓN NORTE DE NARIÑO}

El departamento de Nariño tiene una extensión de $33.268 \mathrm{~km}^{2}$ y está ubicado en el extremo suroccidental de Colombia. La región norte hace parte de una región geográfica conocida como el Macizo colombiano: un nudo montañoso con alta biodiversidad, reservorio de agua donde nacen los ríos más importantes del país (Patía, Cauca o Magdalena). Según el censo (DANE, 2005) en esta región viven 232.755 personas, que corresponden al 13\% del total del departamento.

La condición rural y el aislamiento geográfico del departamento de Nariño, acentuado históricamente por la falta de vías de comunicación, están relacionados con su situación de pobreza, marginalización, abandono y vulnerabilidad frente al conflicto armado (Gobernación de Nariño, 2008: 65). Así, la ubicación geográfica de Nariño lo convierte en una zona estratégica para los diferentes actores armados: su salida al Pacífico y la línea de frontera con Ecuador ha sido usada como corredor para el tráfico de drogas y armas, fuentes financieras del conflicto interno que vive Colombia. Las actividades económicas más importantes de esta subregión están basadas en el sector agropecuario, en el que destacan los cultivos del café, plátano, maíz, yuca, fique, caña de azúcar y frutales (Gobernación de Nariño, 2016).

En el departamento la disputa por la tierra y los cambios en el uso del suelo son una constante relacionada con la inestabilidad de la propiedad y la expansión contínua de la frontera agrícola; dos dimensiones críticas del problema de la tierra, trasnversales al conflicto en el país.

Los procesos de poblamiento en la región norte se dieron en función de los asentamientos indígenas como la mayoría del poblamiento colonial. La estructura de la propiedad y distribución de la población se desarrolló a partir de haciendas, minas y villas. 
Así se configuró el régimen de hacienda de indios mitayos y mestizos encomenderos que daría forma a buena parte de la región y se afirmaría a finales del siglo xvIII (Narváez Ramírez, 2016).

La transición del siglo XVIII al XIX se dio en medio de cambios en la estructura de propiedad, producción, poblamiento y organización política. Las luchas indígenas de múltiples pueblos del departamento, particularmente en el sur y el occidente, como en la hacienda de Bomboná (Yie, 2009) estructuraron el patrón de poblamiento disperso actual del departamento, así como las dinámicas productivas y de intercambio económico a partir del fortalecimiento de la hacienda, el crecimiento poblacional y el desarrollo de la aparcería.

La aparcería tuvo un papel fundamental en el siglo XIx. La hacienda perdía protagonismo en medio del posicionamiento de cultivos de papa, cebada, trigo, maíz, café, fríjol y fique. Estos cultivos posibilitaron la división en distintas unidades productivas más pequeñas que luego configurarían la distribución poblacional y espacial de los asentamientos de forma dispersa sobre las montañas; un rasgo característico del paisaje de Nariño.

En el siglo xx las luchas campesinas tuvieron eco institucional al formularse las primeras e incipientes leyes de reforma como la Ley 200 de 1936 centrada en bienes de eclesiales (Vega, 2002; Archila, 2003). En 1964, con la promulgación de la Ley de Reforma Agraria y Colonización, se dieron procesos de poblamiento dirigido y dotación de tierras, lo que contribuyó al avance de la frontera agrícola (Fajardo, 2001). En este mismo periodo la expansión del cultivo de café fue vertiginosa (Estrada, 2011). Las transformaciones productivas del café permiten comprender buena parte de la organización productiva, de la propiedad y la identidad campesina de la región norte de Nariño. En esta región, a partir de la década de los setenta del siglo xx, las políticas de producción del café han sido fundamentales para organizar y reglar la organización productiva y social de la región, así como el carácter identitario de los campesinos, como caficultores.

\section{PENSAR LO CAMPESINO ENY DESDE EL NORTE DE NARIÑO}

En la literatura, hacer referencia a lo campesino desde los discursos institucionales (Gobernación de Nariño, 2008, 2016) es problemático, incluso en un departamento mayoritariamente rural, por las ambivalencias de las que está cargado este concepto. Como indica Yie (2017), a partir del trabajo etnográfico con distintas organizaciones agrupadas en el naciente Movimiento Agrario de Nariño (ADEL, 2016), un aspecto que debe tomarse en cuenta son las relaciones a las que hace referencia esta noción en contextos situados. Alguna de estas ambivalencias es el posible núcleo que definiría al campesinado 
en relación con la tierra. Entiéndase una forma tradicional de trabajo que no es uniforme y cuyos rasgos de ancestralidad son cuestionados; un tipo de tenencia y estructura productiva cuando esta varía tanto en cantidad como en intensidad de manejo; una forma cultural de vínculo y espiritualidad anclados a la relación con la naturaleza, pero atravesados por temas como los paquetes tecnológicos de la Revolución verde. Incluso la puesta en cuestión de dicho vínculo por actores que reclaman que toda relación con el medio, como una manera de concebirlo y sentirlo como marcadores de identidad, debe pasar por marcos étnicos (Acevedo \&Yie, 2016;Yie, 2016).

Las luchas actuales de los campesinos de la región norte reclaman una noción territorial, situada y anclada al trabajo que hacen para la supervivencia, la provisión de alimentos y la búsqueda de procesos productivos acordes con los ciclos ecológicos de los lugares en donde habitan. Estas búsquedas se enmarcan en las estrategias legales que en la CPC son recursos para la defensa de derechos colectivos a la tierra o incluso mecanismos de participación efectiva. Hoy, a través de la categoría de campesinado, se buscan garantías para el ejercicio efectivo de la participación política y el reconocimiento territorial como base de ordenamientos territoriales desde los territorios, no como instrumentos desde el centro de la Administración pública. Particularmente, busca ser un mecanismo de reconocimiento a partir de criterios culturales que responde a las estrategias que han encontrado otros colectivos en los marcos del multiculturalismo neoliberal abiertos por la CPC en 1991 y las transformaciones estructurales de esa década (Montenegro-Lancheros, 2016). Estas búsquedas de las organizaciones problematizan una idea unificada de campesinado que se expresa, por ejemplo, en las dificultades técnicas para contar y nombrar.

Reconocer quién cuenta, quién hace parte del Estado y cómo es nombrado es central. Un ejemplo clave se encuentra en la acción de tutela interpuesta por 1758 campesinos y campesinas contra el Departamento Administrativo Nacional de Estadística (DANE) y el Ministerio del Interior:

Por la violación al derecho fundamental a la igualdad material (artículo 13 de la CPC) del campesinado, considerado como grupo e individuos, que afecta el goce de sus derechos económicos, sociales y culturales, así como la protección a su proyecto de vida e identidad cultural diferenciada. Esta violación surge por la omisión injustificada de las entidades accionadas de incluir, en el XVIII Censo Nacional de Población y VII deVivienda de 2018, preguntas que indaguen por la identidad cultural diferenciada del campesinado y su situación socioeconómica.

3. Acción de tutela número 1100122040002017-03161-00(148-17). 
El reconocimiento de una categoría censal es también el reconocimiento territorial y político de formas de ordenar, reglar, administrar y habitar que exceden lo que la agenda actual del Estado colombiano está dispuesta a incluir. La tutela buscaba incluir como categoría censal al campesino a partir de la adscripción voluntaria; sin embargo, el DANE no incorporó ni desarrolló mecanismos para su inclusión. Éste es un claro ejemplo de que el problema de la tierra es también una disputa por la participación y el reconocimiento efectivos. Estas discusiones amplían la resolución de los problemas agrarios, con la posibilidad de otros ordenamientos territoriales como alternativas al dilema de concentración de tierra como eje de poder y desigualdad.

Para entender las ambivalencias de esta noción hay que revisar los proyectos y discursos que la atraviesan. La siguiente revisión histórica de los procesos institucionales, construida a partir del marco temporal y analítico de las trayectorias vitales de los campesinos en la zona de estudio, permite entender cómo se ha normado lo rural y las actividades productivas a partir de la perspectiva de la administración económica del espacio. Estos marcos constituyen antecedentes de las lecturas sobre lo rural y lo campesino como categorías de ordenamiento territorial y de ciudadanía.

\section{AGENCIAMIENTOS INSTITUCIONALES, 1850-2019}

Un punto de partida para comprender los usos de la noción de campesinado en Colombia tiene que ver con lo que muchos autores han estudiado como la relación entre la formación del Estado en Colombia y las luchas de actores periféricos al proyecto de nación ${ }^{4}$. Las transformaciones agrarias del país en la transición del siglo XIX se dan a partir de los cambios en la concentración de la mano de obra esclava o indígena en función de los cambios productivos agenciados por el régimen de hacienda a partir de productos como el tabaco o el café (Fajardo, 2001).

Las bonanzas agrícolas configuraron la estructura productiva y las dinámicas demográficas. Las relaciones productivas pasaron paulatinamente de una estructura colonial con carácter de plantación a una de hacienda. Con su desintegración y el desarrollo de la aparcería, se conforma el minifundio de jornaleros agrícolas. De esas transformaciones surge lo que en la literatura se conoce como campesinización y desindianización (Montaña, 2016) para explicar los cambios agenciados por la migración de la población rural, las transformaciones productivas y las políticas de reconfiguración agrícola. Todos estos procesos, sumados a las leyes de tenencia, transformaron el carácter de los habitantes ru-

4. Véase por ejemplo el trabajo de Bejarano (1983) o de LEGRAND (1994). 
rales y las formas productivas del campo. Con la política de enajenación territorial y la ausencia del Estado, las dinámicas fronterizas cayeron en manos de particulares y se afianzó el latifundio. La frontera agrícola se amplió en condiciones de fragilidad estatal (Fajardo, 2014). El siguiente apartado expone los momentos que marcaron institucionalmente los usos y procesos por los que se ha configurado esa categoría. Estos momentos responden a la periodización y contexto del norte de Nariño enmarcado por las trayectorias de vida de los entrevistados y el material consultado.

\section{ORGANIZACIÓN TERRITORIAL, ESTADO Y POBLACIÓN RURAL}

Entre finales del siglo XIX y principios del siglo Xx las luchas agrarias fueron eje de la configuración del Estado y de las relaciones regionales de propiedad y producción. La población protagonista de estas luchas fueron los actores rurales en disputa con los poseedores de la tierra, los medios de producción o la toma de decisiones (Vega, 2002); esos actores rurales que fueron quedando relegados en las trasformaciones productivas o acogidos como trabajadores agrícolas para la estructura de producción más allá de su realidad colectiva. El mestizaje y la hacienda constituyeron dos grandes matrices que permiten comprender en el largo plazo la configuración de un tipo de población habitante de las zonas rurales que quedaba por fuera de los marcos étnicos de lo indio o lo negro. El campesinado en Colombia, desde principios de siglo xx, hace parte de una idea de espacio rural que incluye habitantes, tecnologías, cultivos y políticas.

La economía del café, como proyecto político nacional, se consolidó entre 1930 y 1950 en medio de luchas agrarias, proyectos de modernización incipiente a partir de la estrecha relación con el mercado internacional y la expansión progresiva de la frontera agrícola (Palacios, 2009). A mediados de esta década, en un contexto de violencia caracterizado por el asesinato sistemático de población y en el marco de una guerra bipartidista, el consecuente desplazamiento de población y cambio en la estructura demográfica fueron determinantes en la paulatina transformación de la distribución de un país eminentemente rural a uno urbano. La conformación de una categoría para referirse a los habitantes rurales, cuya organización, demandas y luchas estaban estrechamente vinculadas con la estructura de tenencia y uso de la tierra se dio en medio de las disputas que fueron parte de la formación del Estado desde el siglo XIX (Palacios, 2009).

Hacia la década del treinta del siglo xx la organización productiva y territorial del país se había transformado. La administración del Estado y la distribución de la población rural eran retos para su gestión y consolidación, además del aumento de procesos de organización agraria que agrupaban a los trabajadores agrícolas en las regiones del Sumapaz 
y Tequendama (Vega, 2004). La necesidad de educar a la gente que habitaba en los ámbitos rurales, así como de formar élites regionales y funcionarios de la Administración pública, fueron el contexto para que se conformara la Comisión de Cultura Aldeana entre 1934 y 1936, encargada de realizar estudios que permitieran identificar el carácter de esas poblaciones rurales (Díaz Soler, 1999; Álvarez Hoyos, 2010). Los estudios sobre cultura aldeana funcionaron como estrategia para formar a los cargos públicos y además documentar el estado de los lugares apartados del Gobierno central con el fin de identificar sus condiciones de atraso.

En Nariño, el estudio fue encargado a Jorge Zalamea Borda (Zalamea, 1936). El autor describe el departamento a partir de cuatro categorías, la tierra, el hombre, la relación hombre tierra y el hombre ante la vida. El documento inicia definiendo a la población a partir de caracteres raciales, señalando la escasa o nula disponibilidad de datos estadísticos respecto a la distribución etnográfica del departamento e indica que éste está compuesto por un $50 \%$ de criollos o mestizos, un $30 \%$ de indios, un $10 \%$ de blancos y un tanto más de raza negra (Zalamea, 1936:31).

Las apreciaciones de Zalamea sobre el carácter psicológico de la población, en particular las diferencias sobre la población urbana versus la rural, son trasversales al texto. Puntualiza en las diferencias raciales que se aprecian entre criollos e indios, aunque, cuando se refiere a los indios que habitan en las zonas rurales, los denomina campesinos. La distribución y ubicación de las poblaciones determina la categoría con la que se nombra:

¿Qué contraste con lo que acontece en la población rural! Toda su vida parece dominada por el concepto del bien común y de la prestación mutua de servicios. Si el indio necesita levantar vivienda nueva, no tiene más que poner un tenderete con dos botellas de aguardiente o una barrica de chicha según la región, y solicitar de sus compañeros la ayuda que en otra ocasión pagará con servicios similares. Si es el pueblo o la colectividad la que necesita un camino, antes de que se lo pida dos veces, ya se habrá reunido la población en-minga- y la construcción de la vía no demorará [...] y no se crea que estas mingas son cosa de poca monta o cortos sus alcances [...] los campesinos de La Cruz construyen una carretera de 83 kilómetros sin más pago que la pura satisfacción y la ración de aguardiente como suele estimular el celo de las «mingas» la Gobernación del Departamento (Zalamea, 1936: 35).

También relata el estado de los procesos de colonización y formación de la propiedad a partir de la colonización y trabajo campesinos en la apertura de caminos: Hemos visto como el hombre de Nariño decidió organizar su vida sobre la agricultura y como optó por 
la pequeña propiedad que garantizase al mayor número posible de ciudadanos la independencia económica que de la propiedad se desprende (Ibid: 59). Zalamea, bajo el título de la biología humana, dedica todo un apartado a la descripción de las formas campesinas de vivienda, disfrute y distribución espacial de la familia y las fincas. Cabe resaltar que la población adquiere caracteres distintos, en su descripción, dependiendo de las condiciones geográficas y climáticas donde se hallen esos asentamientos.

El autor coincide en agrupar a todos bajo la idea de campesino, quien habita esas extensiones de tierra dejadas sin administración del gobierno central y cuyas infraestructuras incipientes, como las vías de comunicación, han sido hechas por sus habitantes. Asimismo, las formas en que han buscado resolver sus necesidades de movilidad, conectividad y habitación son marcadores de lo que define al campesinado. En la descripción es clara la ausencia del Estado como organización central del poder y administración territorial.

El retrato de una población rural atrasada, sumida en condiciones de pobreza, ausencia de infraestructura y bajas condiciones sociales, económicas y de salubridad fue parte del diagnóstico que presentaba el texto de la comisión. A pesar de mostrar cierto carácter autónomo en la resolución de condiciones básicas de poblamiento y habitabilidad, sus condiciones de vida eran muy precarias. En este contexto la presencia de la Iglesia en las zonas rurales empezó como un trabajo de extensión misional y caritativo que llevaba alimentos, salud y algunas acciones de alfabetización a las zonas rurales del departamento (Pérez Prieto, 2016; Echeverry, 2017; Büschges, 2018).

\section{DESARROLLOY MODERNIZACIÓN}

En Boyacá, un departamento en el centro del país, surge en la década de los cuarenta por iniciativa del trabajo jesuita Radio Sutatenza. Ésta fue una estrategia radial, parte del programa de alfabetización y formación de los campesinos en Colombia conocido como Acción Cultural Popular (ACPO). A través de la radio se guiaban procesos de alfabetización y formación cívica de los campesinos quienes, desde sus veredas en la casa de un líder local formado por el programa, llevarían a cabo un proceso de escuela a distancia.

El impacto y capacidad del programa se ampliaron hasta convertirse en una estrategia de educación nacional en asociación con el Ministerio de Educación en los sesenta, cuando entran en operación las estrategias de Desarrollo Rural Integrado. Una de las estrategias que construyeron de forma conjunta entre ACPO y el Ministerio de Educación fueron las Concentraciones de Desarrollo Rural (Toledo et al., 1978). Éstas serían escuelas 
en donde, además de la formación básica y secundaria de los procesos de escolarización tradicional, se dieran estrategias integrales de formación y extensión rural para el desarrollo. Una de ellas se ubicó en el municipio de La Unión, en la zona de estudio.

De manera paralela, el trabajo pastoral de los jesuitas en las parroquias en la región Norte fue transformando las acciones de beneficencia en acciones formativas y de acompañamiento local por medio del trabajo de grupos de animadores que visitaban a las comunidades, apoyando el trabajo de los párrocos en el calendario de fiestas y celebraciones religiosas. Por medio de estas estrategias, fueron incorporando una perspectiva del trabajo de Iglesia al servicio de los pobres. La formación de liderazgos y la construcción de una conciencia sobre la dignidad humana se convirtieron en el pilar de la presencia pastoral en el norte de Nariño (Rico, 2013).

La idea de la dignidad humana y, por ende, de las condiciones de vida productiva acordes dio el corte ambiental, agroecológico y asociativo que tendría el acompañamiento al mejoramiento productivo de los campesinos, como parte de las estrategias de desarrollo. Esto se tradujo en tecnologías productivas funcionales a los recursos propios de la finca, a la atención a los ciclos del suelo y el agua como elementos vitales, además del manejo de la finca a partir del cuidado de las condiciones de salubridad del hogar. El acompañamiento técnico en temas de agroecología y formación campesina desde la década de los sesenta estuvo influenciado por el trabajo de Instituto Mayor Campesino (IMCA), una obra de la Compañía de Jesús planteada como una universidad campesina que luego se convirtió en un instituto encargado de la promoción social con enfoque de desarrollo rural integrado en los setenta.

Estos dos programas fueron altamente influyentes en la zona. La creación de asociaciones, cooperativas y grupos de trabajo fue expresión de las estrategias de intervención y desarrollo, sumadas a las condiciones locales y necesidades de los campesinos, que, como indicaba Zalamea en su texto décadas atrás, destacan por su capacidad de pensar en colectivo y asociarse para resolver necesidades comunitarias donde predomina el concepto del bien común.

Durante la década de los sesenta se impulsó un programa de reforma agraria contemplado en la Ley 135 de 1961. Esta iniciativa respondió a la valoración de los efectos de la concentración de la propiedad agraria en la inestabilidad política y en los conflictos armados, tanto por parte de un sector de las élites como del Gobierno norteamericano, quien promovía la reforma a través de la «Alianza para el Progreso». Ésta fue una estrategia desde donde apoyó y orientó la reforma agraria colombiana, con notorio interés en neutralizar la influencia del pensamiento socialista (Díaz Fariñas, 2013). 
Esta ley dio paso a la creación del Instituto Colombiano para la Reforma Agraria (INCORA), encargado de la dotación de tierras por fuera de la frontera agrícola y la poca intervención a la gran propiedad. La modernización sería a través de la intensificación de la producción por medio de programas de crédito de la mano de los programas de dotación (Machado, 1999). La definición de los rubros productivos en los que se concentrarían territorialmente se dio en función de las condiciones climáticas y las perspectivas para el mercado.

En el norte de Nariño se reparte la hacienda Dalmacia dando créditos para la producción de maíz de las tierras más bajas en la frontera con el Cauca. En las zonas más altas, que se poblaron a partir de distintas oleadas migratorias por los movimientos del volcán Doña Juana y la ruptura de distintas haciendas desde la década de los veinte, se cultivaba fique (Furcraea andina) como producto comercial y café en menor medida. La intensificación del cultivo del fique como cultivo comercial se dio por medio de los créditos de la Caja Agraria. La dotación y el crédito como estrategias de modernización serían herramientas de gestión del espacio a partir de criterios productivos y económicos. Lo que pasaba territorialmente se reglaba a partir de las condiciones productivas y perspectivas de comercialización que se sustentarían en los trabajadores agrícolas.

\section{LA ECONOMÍA DEL CAFÉY LA CONFIGURACIÓN DE IDENTIDADES PRODUCTIVAS}

En la década de los setenta el fortalecimiento a la economía del café fue fundamental. La expansión a nuevas zonas de cultivo y su afianzamiento bajo el paquete tecnológico de la variedad Colombia (Castillo \& Moreno, 1987), que devino de la Revolución verde y las modificaciones implementadas por la demanda en calidad y criterios de eficiencia, dieron como resultado la intensiva presencia de la Federación Nacional de Cafeteros de Colombia (FNCC) en las zonas de menor producción o fuera de los circuitos tradicionales como el eje cafetero (Guhl, 2008; Palacios, 2009).

En el norte de Nariño se ha producido café desde la década de los treinta (Fig. 2). Sin embargo, en la década de los setenta, la implementación de paquetes tecnológicos de la variedad Colombia y la intensificación de la producción dieron otra perspectiva técnica a los campesinos y a los proyectos sobre lo campesino. El perfil de caficultor, como un carácter identitario, permeaba dicha noción desde los discursos gremiales. 


\section{FIGURA 2}

Mapa del café de la República de Colombia, 1939

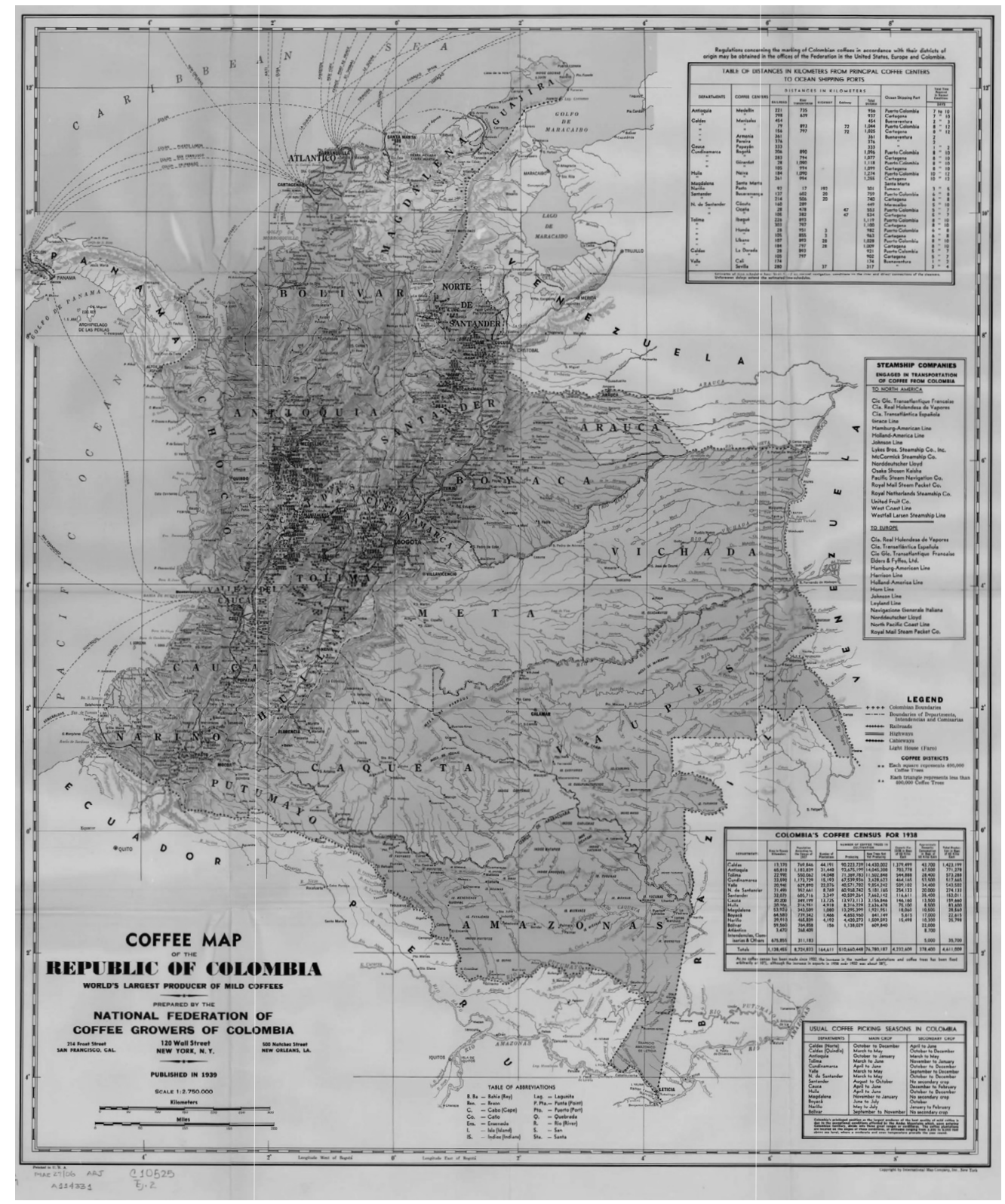

Fuente: colección de cartografía histórica digital del Banco de la República (http://babel.banrepcultural.org/ $\mathrm{cdm} /$ singleitem/collection/p17054coll13/id/101/rec/1). 
Los proyectos de caficultura basados en un perfil productivo centrado en el mercado internacional, regido a partir de criterios de eficiencia, se tradujeron cotidianamente en café intensivo y sin sombra. Estos proyectos contrastaron con la trayectoria productiva de Nariño, enfocada en distintos productos alimentarios; una forma productiva característica de las economías campesinas (Corrales \& Forero, 1992; Santacoloma, 2015). El café pasó de ser un cultivo alimentario familiar y de comercio menor a ser puramente comercial -en algunos casos- para finales del siglo Xx. Este manejo productivo, a través de cultivos diversificados y bajo sombra, es el que da en la actualidad las características especiales al grano, las mismas que constituyen uno de los ejes de valor para las compradoras y tostadoras del mundo que llegan a la zona. Este conjunto de intervenciones institucionales, programas y proyectos tuvo impactos muy importantes en la vida cotidiana de los campesinos. A través de su trayectoria de vida es posible dimensionar, tanto los cambios en los usos del suelo como en el perfil productivo que generaron estos programas de intervención rural. Ejemplo de ello el relato que hace Raquel, una mujer campesina del municipio de San Lorenzo:

Todo lo que hay hoy en café en ese tiempo era cabuya, por ahi quedan unas maticas, eran unas matas grandotas. Mi mamá comenzó a sembrar café caturra cuando yo tenía como dieciséis años, como en los setenta. En esa época se sembró de ese porque un técnico que se llamaba Guillermo, de la Federación, trajo esa variedad. Me acuerdo porque en esas épocas venía a visitar a mi mamá. Por esa época mi mamá nos mandaba donde un primo, allá tenían de esos árboles de café grandes y ellos venían a ayudarle a mi mama a descontar la mano prestada, como se dice. A ayudarle a hacer los semilleros, a huequiar para sembrar el café nuevo. La caña también se sembró harto porque hubo créditos de eso del DRI $I^{5}$, pero se perdió porque no hubo comercio.

De manera paralela, las estrategias de desarrollo rural y acompañamiento pastoral proponían a los campesinos narrativas y prácticas sobre la forma de producir, a partir de nociones de bienestar y producción con base en principios agroecológicos. Los cultivos alimentarios fueron un elemento clave para el sostenimiento de la economía y la alimentación, así como para la conservación del suelo y el agua. Los discursos de la FNCC abogaban por la eliminación de otras plantas que pudieran obstaculizar el cultivo comercial del café, bajo las perspectivas técnicas de los paquetes de entonces. Estos discursos se encontraban con las narrativas y prácticas de los campesinos en sus fincas, con la distribución en pequeños lotes dispersos por la montaña debido a los patrones de asenta-

5. Las estrategias de desarrollo rural integrado, como políticas de crédito y acompañamiento técnico. 
miento que conforman una finca en el norte, y con la presencia de cultivos alimentarios en medio del bosque (Rico, 2016).

Entre los años setenta y ochenta, la noción de campesino hacía referencia a una categoría nominal de un tipo de actor productivo asociado a labores agrícolas. Este carácter productivo y funcional fijaba el acceso a la tierra con créditos para el abastecimiento de las ciudades o de acceso a tierras ampliando la frontera agrícola. Los efectos de estas iniciativas fueron limitados frente a los factores estructurales de los conflictos. Adicionalmente, su arraigo en los desequilibrios económicos y políticos se profundizó con el ingreso de los recursos del narcotráfico y el desarrollo de la guerra encubierta, donde el paramilitarismo jugó un papel central en la neutralización de las fuerzas de oposición política de izquierda y de control territorial dentro de nuevos círculos de violencia (Fajardo, 2014).

En la década de los ochenta se afianzan nuevos procesos productivos asociados a los cultivos de uso ilícito y los contextos de desplazamiento forzado por distintos actores, vinculados con las disputas por el control territorial y el recrudecimiento del conflicto armado. Durante los noventa estos problemas se sumaron al abandono de las estrategias de desarrollo rural y reforma agraria reemplazadas por las reformas estructurales neoliberales, que dejaron en el mercado las funciones de regularización, distribución y uso de la tierra. El control de la propiedad reafirmó que la tierra es la fuente del poder en Colombia (Centro Nacional de Memoria Histórica, 2013). Los esfuerzos de reforma agraria se tradujeron en políticas de flexibilización del trabajo para facilitar la inserción a los mercados. La población rural, conceptuada hasta ahora como campesinos, empieza a ser nombrada a través de nociones como pequeño productor.

\section{REFORMAS ESTRUCTURALES: DE LA NOCIÓN DE CAMPESINO A LA DE PEQUEÑO PRODUCTOR}

La focalización de las políticas sociales a través de estrategias de alivio a la pobreza marcadamente asistencialistas fue el punto de quiebre del abandono del Estado a las tareas de reforma agraria. Las reformas estructurales de los noventa trajeron la desatención a las tareas sociales del Estado y la configuración de un perfil de ciudadanía para los campesinos completamente alejado de sus derechos agrarios, y más próximo a sus capacidades de emprendimiento y productividad. El multiculturalismo se convierte en el marco político para la construcción de ciudadanía y nociones de derecho. En 1991 se redacta una nueva constitución, producto de movimientos ciudadanos y presiones sociales, que brinda marcos para la participación y las garantías desde el reconocimiento a comunidades indígenas y afros como colectivos. Además, plantea algunos elementos para definir el re- 
conocimiento territorial de los campesinos, más allá de una idea de trabajadores rurales, como se expresa en el documento, con base en la adjudicación de derechos agrarios colectivos a través de la figura de ZRC (zona de reserva campesina).

A partir de la Ley 160 de 1994, una ZRC se define como figura preferencial para fomentar la pequeña propiedad rural, regular la ocupación y aprovechamiento de las tierras baldías de la Nación - de la mano de la titulación a campesinos de escasos recursos-, en el marco de la conservación ambiental y de los recursos naturales y el ordenamiento territorial (Constitución Política de Colombia, 1991). Algunos autores la han estudiado como una herramienta política para la identificación territorial del campesinado como un actor político al que se reconoce un territorio como parte de su identidad colectiva (Pérez, 2007; Ordóñez Gómez, 2012).

Este avance, en un contexto que paulatinamente afianzaría el desconocimiento al campesinado, fue agenciado por organizaciones campesinas locales, municipales y nacionales, que adquieren mayor visibilidad y capacidad organizativa a través de estrategias de visibilización y lucha. En esta década, además, el contexto nacional empieza a ser un terreno hostil para las organizaciones comunitarias por la creciente violación de derechos humanos y el avance de intereses protegidos por grupos armados legales e ilegales, particularmente a partir de la firma del Plan Colombia y los periodos presidenciales de Uribe Vélez (Ramírez, 2009; Vega, 2015). En la década de los dos mil, el incremento exponencial de los cultivos de uso ilícito, la expropiación legal e ilegal de tierra por medio de la fuerza y la violencia, en función de intereses de inversión trasnacional, afianzaron el control territorial de distintos actores armados en el campo y las estrategias de despojo como formas de concentración de la propiedad (Reyes, 2016).

La explotación de recursos naturales en una década de reprimarización (Bonilla, 2011) marcó un giro en la agenda política. Esto se sumó al interés de distintas organizaciones e instituciones en visibilizar conflictos ambientales relacionados con problemas de conservación, autonomía, explotación y disfrute de sujetos colectivos. Estos conflictos agudizaron los temas irresueltos de la agenda agraria décadas atrás. La crisis en los precios y garantías para la comercialización que expresaban los gremios, sumadas a los múltiples incumplimientos en acuerdos con los movimientos y organizaciones campesinas caldearon el escenario para que en 2013 se organizara el Paro Agrario (Salcedo, 2013). Durante un mes de movilizaciones los campesinos presionaron por la conformación de la Mesa de Interlocución y Acuerdo (MIA) con el Gobierno nacional.

Un año antes se había llevado a cabo el Foro Agrario en el que participaron numerosas organizaciones, académicos e instituciones del Estado con el fin de discutir y acor- 
dar posibles respuestas a la crisis que se anunciaba. Como resultado, se identificó la necesidad de un censo agropecuario y la urgencia de estrategias de ordenamiento social y ambiental del territorio, propuestas que debían materializarse a través de decisiones políticas. Desde 2003 a través del Mandato Agrario promulgado en el Congreso Nacional Agrario, las organizaciones campesinas agrupadas en el Coordinador Nacional Agrario (CNA), presentaron un documento donde reclamaban el derecho a la vida, la soberanía alimentaria y la territorialidad. En este documento quedó expresada la necesidad del reconocimiento formal no sólo de la tierra, sino del territorio a las comunidades campesinas y particularmente su reconocimiento político, como quedó consignado en el punto nueve del documento (CNA, 2015).

\section{LUCHAS POR LA IDENTIDAD CAMPESINA Y LOS DERECHOS TERRITORIALES}

Un antecedente importante, dentro de los esfuerzos de la sociedad civil a nivel internacional, que ha tenido un impacto central en la región, fue la declaración de los derechos de campesinas y campesinos que presentó la Vía Campesina en su quinta conferencia en 2008 con el fin de construir una convención internacional. En 2013 el grupo de trabajo organizado por la Organización de las Naciones Unidas promulga la "Declaración sobre los derechos de los campesinos y de otras personas que trabajan en las zonas rurales».

Esta declaratoria reconoce al campesinado como un grupo social específico que tiene una relación especial con la naturaleza a través de la producción agrícola. Este reconocimiento exhorta a que le sean garantizados, individual y colectivamente, los derechos a la tierra y el territorio, así como la participación efectiva y la protección de los valores de la agricultura, entendida como el conocimiento histórico y cultural sobre los procesos agrícolas locales.

El documento del CNA fue clave para las organizaciones campesinas en las regiones. Desde Nariño se aportaron elementos centrales a partir de la gestión de organizaciones comunitarias como el Comité de Integración del Macizo Colombiano (CIMA). Esta serie de documentos han ido a la par de las estrategias locales para el reconocimiento de los territorios y el posicionamiento de sus demandas en la agenda política a través de propuestas de gestión territorial más allá de las ZRC establecidas o proyectadas. Una de estas propuestas locales, que ha tenido amplia resonancia en el escenario nacional, es la figura de Territorio Campesino Agroalimentario (TCAM) (Fig. 3) promovida por el CIMA en el Macizo, región geográfica que incluye al norte de Nariño, promulgada en San Lorenzo en 2016 (Cely, 2018). 


\section{FIGURA 3}

Delimitación de la propuesta de TCAM del norte de Nariño y sur del Cauca
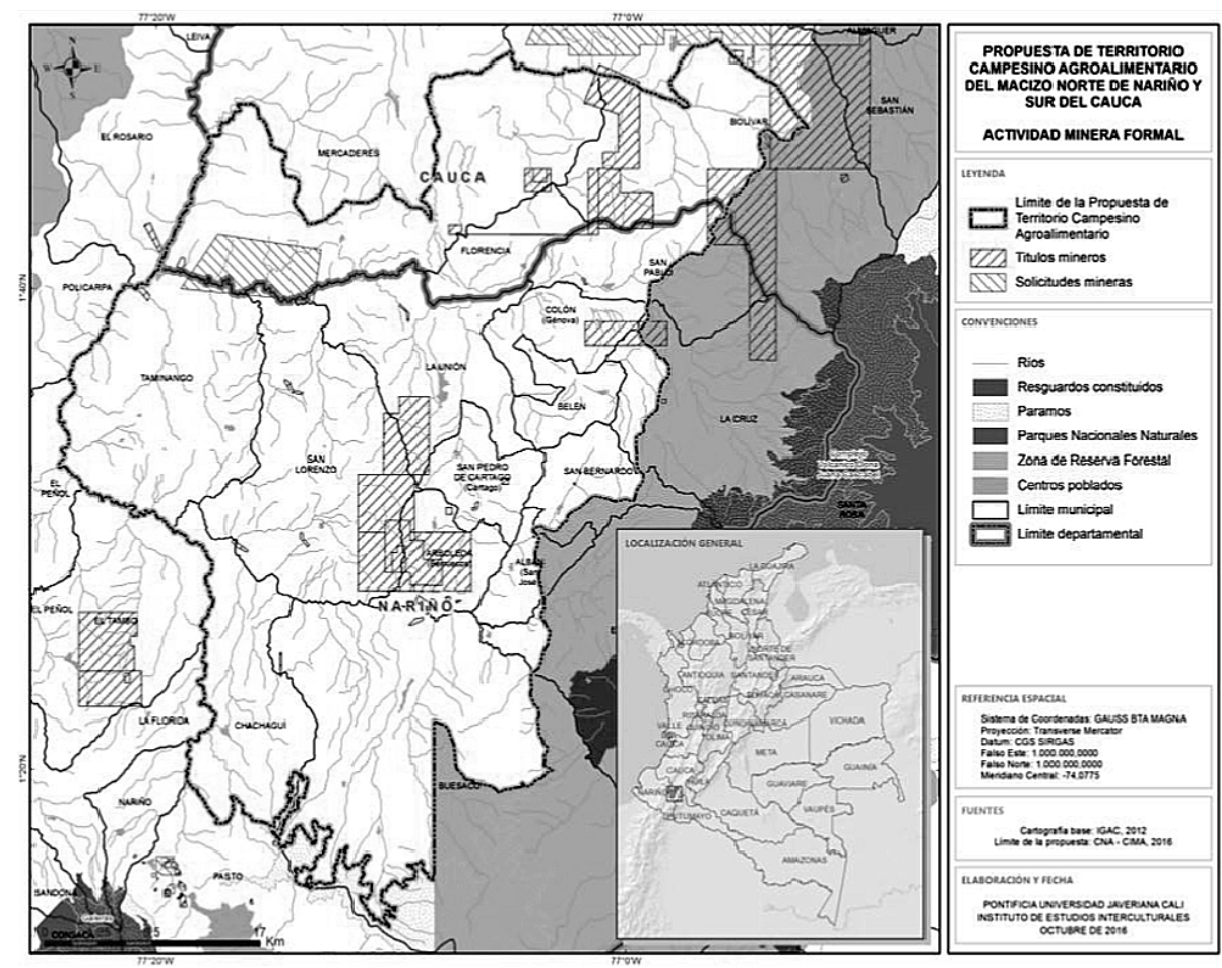

Fuente: elaborado por Dayver Betancourt (https://asillavacia.com/silla-llena/red-rural/historia/los-territorios-campesinos-agroalimentarios-59671\#_ftn2).

Los TCAM son una propuesta de ordenamiento territorial, ambiental y económico para el reconocimiento político de los campesinos a partir de zonas específicas para el desarrollo exclusivo de actividades relacionadas con la economía campesina, salvaguardando así sus tierras de actividades extractivas, minero-energéticas o de intentos de despojo y desplazamiento.

Se trata de territorios habitados por campesinos, dedicados (no de forma exclusiva) a la producción agrícola y pecuaria en pequeña escala, pesca y sistemas silvopastoriles, así como pequeña minería combinada con agricultura. Aqui los productos generados sirven a la satisfacción de las necesidades propias del campesinado, así como de la población que no habita el mundo rural (CNA, 2015).

Esta propuesta se gestó desde las pequeñas organizaciones comunitarias de la región norte de Nariño a través de prácticas de organización, gestión, producción y reconoci- 
miento afianzadas en su vida cotidiana. Durante décadas de pugnas y movilización, fueron escalando distintos escenarios hasta convertirse en temas de la agenda del debate agrario, que desde los noventa había abandonado la atención a las necesidades sociales del conflicto por la tierra. La mayoría de las respuestas instituciones se habían centrado en concebir soluciones de modernización y desarrollo empresarial a través del mercado. Las políticas de restitución, retorno y reparación que se dan a finales de los noventa en atención a las víctimas del conflicto armado transformaron sustancialmente el foco de los esfuerzos institucionales (Ministerio de Agricultura y Desarrollo Rural, 2012). Salgado (2012) señala que estos esfuerzos no tomaban en consideración los actores que ejercen mayor control sobre los territorios, los campesinos, reproduciendo así el viejo esquema del desarrollo rural como estrategia de atención a la pobreza.

Las propuestas como los TCAM desde las organizaciones del norte de Nariño plantean nuevos retos y posibilidades dentro de los marcos del reconocimiento o las políticas de producción de identidades rurales. Estos mecanismos demarcan a los campesinos a partir de un carácter meramente productivo al servicio de los intereses del capital, movilizados a través de estrategias de inserción productiva, desconociendo el carácter de las luchas por la ciudadanía que subyace a las demandas y propuestas de las organizaciones comunitarias de la región.

En este escenario las discusiones de los acuerdos de La Habana en 2016 para la terminación del conflicto armado entre las FARC y el Gobierno nacional, particularmente el punto uno referente a la Reforma Rural Integral, ampliaba los términos en los que el problema de la tierra era referido desde hace más de una década. El Foro Agrario de 2012 había establecido puntos específicos relacionados con el reconocimiento territorial y comunitario del campesinado, producto también del mandato de 2003. Esta serie de instrumentos agenciaron su reconocimiento como parte del pliego de la MIA, reafirmando la necesidad de incorporar dentro de las estrategias de atención al conflicto agrario, una perspectiva territorial que englobara el reconocimiento de la ciudadanía.

En 2017 la Agencia Nacional de Tierras en atención al punto uno del acuerdo final, desarrolla el Decreto Ley 902, por medio del que se busca agilizar los procesos de acceso y formalización de la propiedad rural como aporte a la materialización del derecho a la paz. Este esfuerzo propuso los mecanismos y ajustes normativos para garantizar la seguridad jurídica y la progresividad en el acceso a la tierra a partir de una estrategia de barrido predial en las zonas priorizadas. Los beneficiarios del fondo de tierras se determinarían a partir de la realización de un catastro multimodal. Este mecanismo también permitiría la implementación del Plan Nacional de Sustitución de Cultivos de Uso Ilícito (PNIS) y los Programas de Desarrollo con Enfoque Territorial (PDET). Los suje- 
tos beneficiarios serían campesinos, campesinas, trabajadores y trabajadoras de la tierra (Agencia Nacional de Tierras, 2017) que no tengan propiedad o carezcan de la cantidad suficiente para garantizar su bienestar.

El Decreto reconoce la economía del cuidado, como el aporte del trabajo femenino en la economía familiar y campesina, y establece los mecanismos para priorizar los procesos de dotación y formalización a través de las mujeres rurales. El cuidado se reconoce esencialmente como un trabajo femenino. Esta iniciativa centra la resolución del problema agrario, de acceso y control territorial, en un problema de formalización del mercado de tierras. La disputa por el reconocimiento se mantiene, pues así como avanza en reconocer que hay una relación directa entre conflictos por la tierra y violencia, también aporta los mecanismos técnicos para quitar el peso político a las luchas agrarias y por ende a la reivindicación política del campesinado.

En el actual periodo de gobierno (2018-2022) las políticas de atención al campo y las relaciones con lo rural están marcadas por una agenda política centrada en retomar las tareas y lineamientos ultraconservadores que el uribismo puso en la mesa (González, Bolívar \&Vázquez, 2002; González, 2014). Entre estas acciones destacan la criminalización de la protesta social; la regresión en políticas sociales y ambientales; el retroceso en la política de atención a los cultivos de uso ilícito al promover la aspersión aérea de glifosato; además del desconocimiento y la búsqueda constante del desmonte de los Acuerdos de La Habana ${ }^{6}$ (Lewin \& Vélez, 2019). A este escenario se suman una agenda económica y de desarrollo centrada en la reprimarización y explotación de los recursos naturales con mínimas regulaciones. Estas condiciones proponen un contexto hostil para las organizaciones campesinas y las posibilidades del reconocimiento de su participación política, referenciándolas como pequeños productores con necesidad de incentivos económicos, no como campesinos con derechos agrarios.

\section{RECONOCIMIENTO POLÍTICO DEL CAMPESINADO: UN DEBATE ABIERTO}

Las organizaciones campesinas de orden nacional y regional propusieron un capítulo campesino para el actual Plan Nacional de Desarrollo (PND) ante el Consejo Nacional de Planeación como una hoja de ruta en el actual periodo de gobierno. La propuesta titulada «Pacto por la equidad rural y el bienestar de la población campesina» buscaba incluir

6. Sobre el texto final del acuerdo véase Gobierno Nacional de Colombia, FARC-EP y países garantes (2016). 
medidas y programas específicos que permitieran a los campesinos tener derechos en condiciones de igualdad dentro de las bases del PND actual (DNP, 2019):

Sólo tienen en cuenta al campesinado en asuntos de desarrollo agropecuario y rural; educación y participación ambiental; y resolución de conflictos interculturales. Por su parte, la propuesta campesina abarca ocho líneas estratégicas: (i) acceso, formalización y territorialidades campesinas-áreas protegidas; (ii) fortalecimiento de la economía campesina y adecuación institucional; (iii) acceso a derechos; (iv) infraestructura productiva; (v) cultivos de coca, marihuana y amapola; (vi) ambiente y cambio climático; (vii) mujer campesina; y (viii) jurisdicción agraria (Guïza \& Torres, 2018).

La propuesta pretendía construir un apartado para los campesinos a partir de sus necesidades y procesos organizativos en un esfuerzo por marcar una agenda global desde la trayectoria territorial de una multiplicidad de organizaciones. Sin embargo, el enfoque de las bases del PND actual desconoce al campesinado como una noción clave y la reemplaza por el reconocimiento de la pequeña producción. Al ser reconocidos como pequeños productores, se los hace dependientes de la articulación con la agroindustria, encabezada por el impulso de cadenas de valor, en donde deben insertarse como pequeños productores a través de alianzas estratégicas guiadas por el interés del gran capital inversionista.

La garantía a los derechos de participación y la atención a los ejes del conflicto que atraviesan los problemas por la tierra en Colombia, expresados en las líneas estratégicas del pacto, se pretenden resolver vía procesos de titulación para garantizar las condiciones comerciales para ese modelo productivo. Lejos se está de proponer una estrategia transversal que incorpore los Acuerdos sobre la Reforma Rural Integral. El campesinado queda relegado en un rol residual sometido al modelo de alianzas productivas que se pretende imponer (Mojica, 2019) como sujeto de ordenamiento para la seguridad jurídica de la propiedad, desagrarizando el problema de la tierra y su propiedad como reconocimiento de la participación efectiva.

En el norte de Nariño hoy el énfasis productivo está puesto en el rubro de los cafés especiales. Múltiples instituciones nacionales, eclesiales o de cooperación para el desarrollo están apostando por articular estrategias de desarrollo y pacificación a través del café en la zona. Durante décadas el café convivió con otros cultivos; poco a poco pasó de ser un cultivo alimentario a ser la fuente principal de ingresos. Esto significó su integración dentro de la dinámica de la agricultura de subsistencia, donde la diversidad en cultivos y el bosque han sido parte fundamental de la vida cotidiana y ahora de los elementos que dan 
cualidades especiales al café. Esta serie de valores sensibles asociados al café hacen parte de los códigos de valor que el mercado demanda. Estas transformaciones en el gusto y los elementos que dotan de valor al producto dieron relevancia a la producción artesanal en microlotes, con sombrío y poca agua, que predomina en la zona (Figs. 4 y 5)

\section{FIGURA 4}

\section{Detalle de la distribución de fincas en San Lorenzo. Nariño, 2016}

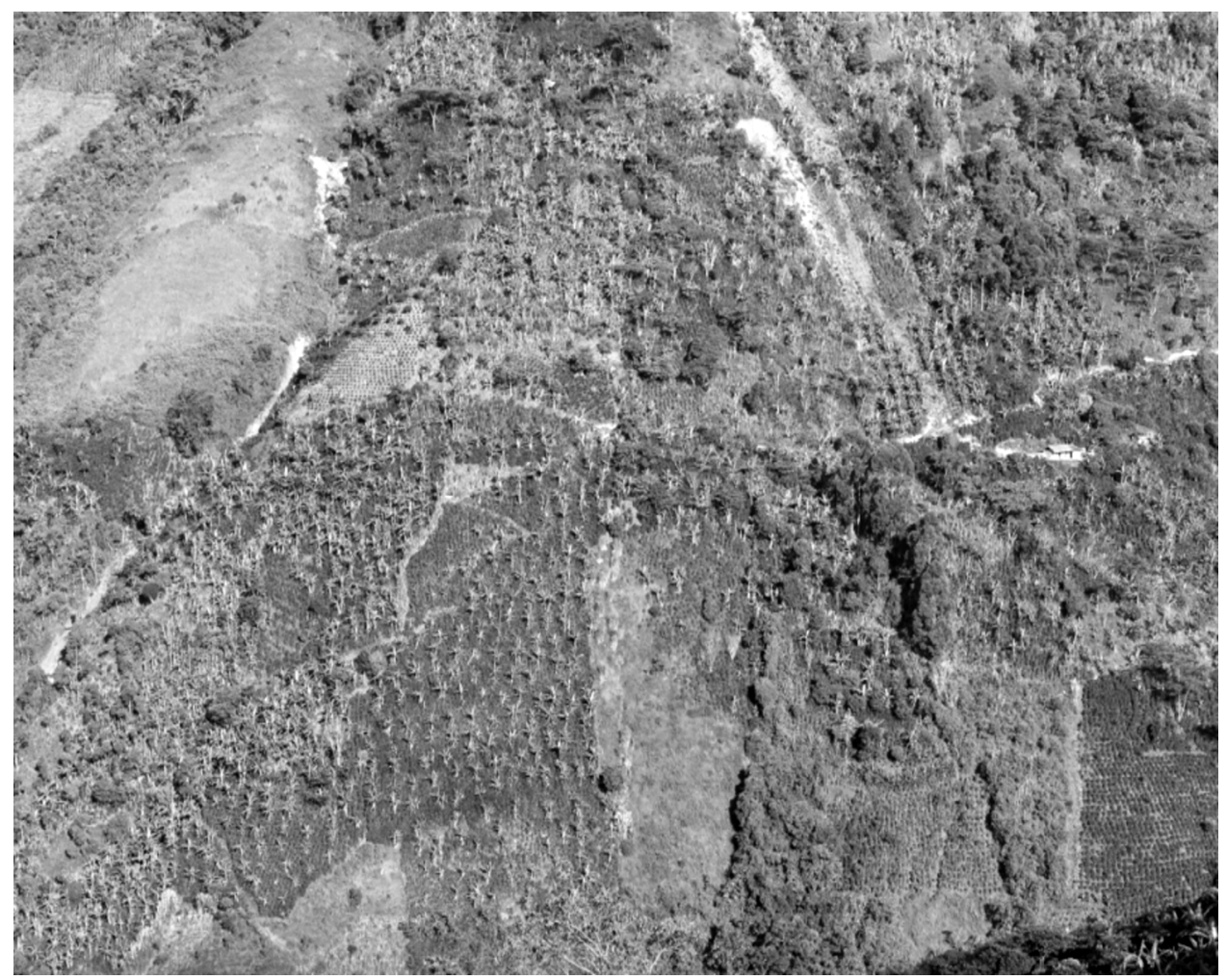

Fuente: fotografía propia.

Las entidades de cooperación han jugado un rol fundamental como intermediarios de los compradores, al poner en valor las prácticas de los campesinos o al ser su guía para ajustarlas a los gustos y condiciones impuestas por los compradores; la trazabilidad de un producto se convierte en garantía de bienestar. Ahora bien, que el café, además de ser un producto a través del cual posicionar un proyecto de economía nacional conectada o dependiente del mercado internacional, sea ahora una estrategia de desarrollo local y pacificación, agenciada por organizaciones de cooperación en alianza con un Estado distante o ausente, plantea preguntas sobre lo que podría entenderse como proyecto de desarro- 
llo: como proyecto territorial sobre cómo reglar y organizar el campo y de la forma en que las estrategias de comercialización son garantía ya no solo de desarrollo, sino de paz. Esto es parte del modelo que plantea el actual PND.

FIGURA 5

\section{Detalle de las fincas en Taminango, 2018}

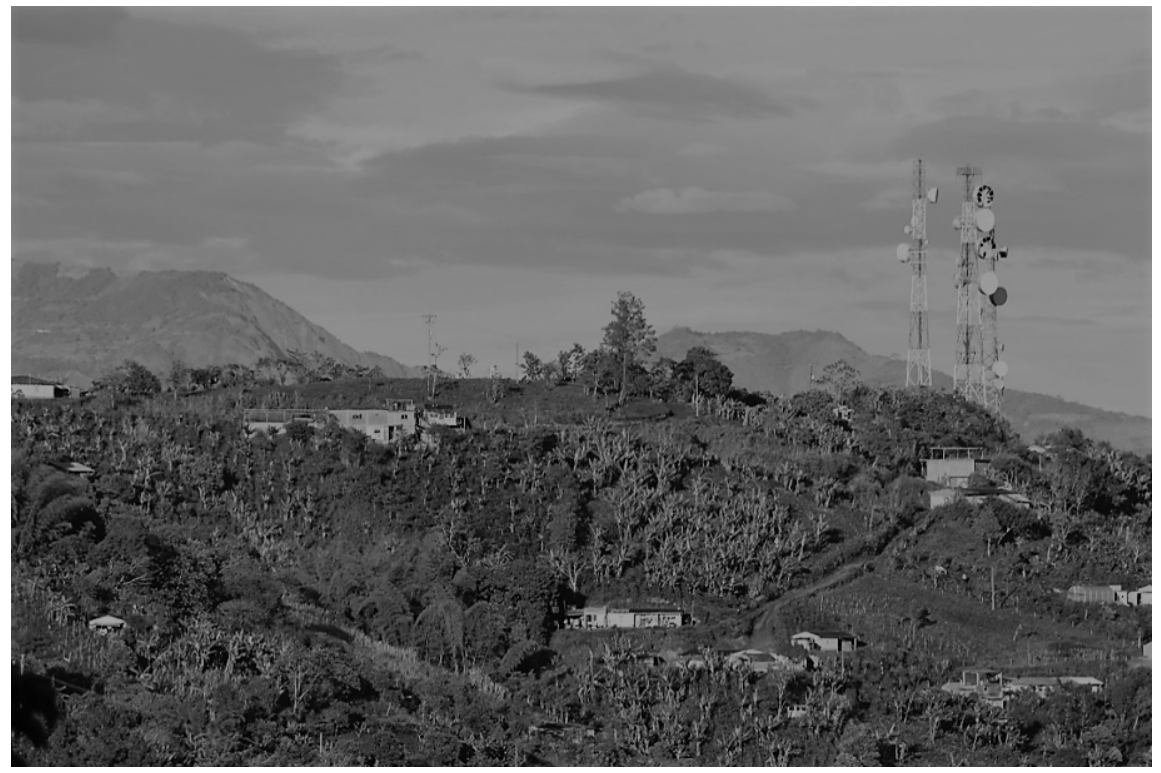

Fuente: fotografía propia.

En esta región las organizaciones campesinas han buscado a través de mecanismos, como la propuesta de TCAM, el reconocimiento colectivo de sus derechos territoriales en medio de la búsqueda por otros procesos productivos e identitarios que no dependan de la economía del café o de los modelos de desarrollo que los marcan como proveedores de materias primas en un encadenamiento de alianzas estratégicas. La diversidad productiva de las fincas, la identidad territorial y el conocimiento cultural sobre la agricultura en esta región hacen parte de los elementos que se ponen en relevancia desde las organizaciones para frenar el avance de los intereses mineros, extractivos o de inversión sobre sus territorios. La importancia del reconocimiento territorial y colectivo de sus derechos garantiza la protección de sus modos de vida y su reconocimiento como ciudadanos con derechos agrarios y sociales. En esta región, es clave comprender la noción de campesino como una categoría territorial no solamente porque es una categoría de ordenamiento espacial de las relaciones y de los intercambios de la vida cotidiana, sino además porque funciona como mecanismo para garantizar el reconocimiento formal de ciudadanías de derecho. 


\section{REFLEXIONES FINALES}

Duarte (2015) propone comprender cómo se desarrolla la categoría de campesinado para designar a los habitantes rurales fuera de los marcos étnicos, que en Colombia remiten a connotaciones políticas de ciudadanía y agrarias después de los noventa. En su interpretación propone hablar de procesos de etnogénesis, es decir, una lectura cultural que conciba al campesinado como producto de la historia rural de colonización, la tradición cultural y la intervención política del Estado en Colombia.

Las políticas de atención, control o intervención de lo rural, además de las dinámicas regionales de colonización y conformación de realidades productivas, no son homogéneas en el país. Los matices regionales permiten comprender por qué hoy la categoría de campesinado es tan esquiva, no resiste homogeneizaciones. Esto en el contexto actual, que se disputa su reconocimiento institucional y político, parece una señal de inoperancia para algunos sectores de la política nacional. Esa misma diversidad es la que constituye su carácter y la que permite usarla como corolario de la historia agraria del país, de los conflictos y disputas por la noción de ciudadanía e incluso poner en entredicho los proyectos y la idea de Estado hoy.

Vale la pena señalar que estas narrativas y proyectos no han sido siempre coherentes o dirigidos. Justamente han sido parte de lo que ha estado siempre en disputa y formación. Quién es el Estado y cómo se desdobla cotidianamente (Joseph, Nugent \& Vargas, 2002) podrían ser preguntas que ayuden a un debate más profundo en este sentido. Es importante entender, particularmente para el contexto del norte de Nariño, el papel de la FNCC en la forma en como el Estado y sus instituciones han estado presentes y cómo ello habla de la fabricación de políticas de producción agrícola -vinculadas además con estrategias educativas y de desarrollo durante décadas, como se referencia en la zona de estudio- como formas de gestión de los espacios rurales.

Las políticas de reforma agraria, la política de tierras y los proyectos de desarrollo rural, además de las estrategias de atención a la pobreza y desarrollo, son relevantes como marcos reguladores del espacio y como proyectos de territorio. La mayoría de estos marcos han sido esfuerzos para remediar el problema de la tierra, entendido como un problema económico y de atraso productivo, obviando que la disputa es por quién tiene poder y control territorial.

Dichas iniciativas son órdenes territoriales pensados para reglar el espacio y ejecutar acciones genéricas desde lo que debe ser productivo y eficiente en términos económicos. Justamente el carácter territorial se adquiere cuando se reconoce que allí habitan comu- 
nidades y son éstas quienes constituyen el carácter de uso y propiedad, y este carácter excede una noción de propiedad de la tierra. Asimismo, es central reconocer que, al reglar ese carácter de propiedad, también se están reglando modos de vida o formas de habitar que exceden cualquier idea o proyecto de administración desde el Estado

Estos marcos, al obviar o desatender en principio el reconocimiento de la ciudadanía para quienes viven en el campo y la necesidad de ordenamientos territoriales desde el territorio, perpetúan relaciones de desigualdad, bases del conflicto en Colombia. El problema no solo es la administración territorial y económica del suelo y los recursos a partir de nociones de eficiencia, pensando en principios muy particulares de riqueza y economía. Cuando se construyen estrategias desde estas únicas perspectivas se agencia que, en regiones como Nariño, el café se convierta en un mecanismo indiscutible de desarrollo, modernización, pacificación e identidad productiva. Asimismo, se corre el riesgo de desdibujar las luchas por las condiciones de producción, derechos agrarios y ciudadanía que sustentan sus condiciones de productividad en la precariedad e incertidumbre de la tenencia.

No se trata únicamente del reconocimiento de los derechos de propiedad y un tipo de uso a través de la formalización, como se ha buscado a través de las estrategias jurídicas institucionales. La lucha de las organizaciones comunitarias hoy, como muestra la propuesta de TCAM por ejemplo, habla de la búsqueda por el reconocimiento a la existencia territorial que se expresa en múltiples formas de habitar, más allá de las actuales reglas del mercado. Atender el problema agrario debe ser un instrumento de equidad (Benítez, 2005). La tierra ha sido un instrumento de control del territorio por actores armados que atienden a los intereses de quien adquiere el dominio. Las estrategias de resistencia local de las comunidades campesinas responden a estas desigualdades. Los esfuerzos en estos marcos institucionales se han convertido en mecanismos que distancian o limitan aún más la democratización de la tierra y la profundización de la exclusión de los campesinos. El interés en la función social y cultural de la propiedad con base en una lectura territorial es un debate que debe ser puesto en la agenda como un tema nodal hoy teniendo como eje las experiencias e intereses locales, expresados a través de las estrategias de las organizaciones comunitarias como las de la región norte, por ejemplo.

\section{AGRADECIMIENTOS}

Queremos agradecer al comité editorial de Historia Agraria, a los evaluadores, así como a todas las personas involucradas en la construcción de la versión final de este manus- 
crito. De igual manera, queremos expresar nuestro agradecimiento a las y los campesinos de Nariño: la trayectoria de sus luchas inspira este trabajo.

\section{REFERENCIAS}

Acevedo, M. J. \& Yie, S. M. (2016). Nos debemos a la tierra: El Campesino y la creación de una voz para el campo, 1958-1962. Anuario Colombiano de Historia Social y de la Cultura, 43 (1), 165-201.

ADEL (2016). Elementos de formación del campesino como sujeto político: Movimiento Agrario de Nariño. Proyecto fortalecimiento organizacional del movimiento agrario Fase I en el departamento de Nariño. San Juan de Pasto: Gobernación de Pasto.

Agencia Nacional de Tierras (2017). El Decreto 902 de 2017: Una apuesta institucional para consolidar la paz. http://www.agenciadetierras.gov.co/wp-content/uploads/2018/04/Decreto-902-de-2017-Una-Apuesta-Institucional-para-consolidar-lapaz.pdf

Agrawal, A. (2005). Environmentality: Technologies of Government and the Making of Subjects. Durham: Duke University Press. (New Ecologies for the Twenty-First Century).

Álvarez Hoyos, M. T. (2010). La campaña de Cultura Aldeana y su impacto en la cultura nariñense. En Academia Nariñense de Historia, Manual Historia de Pasto (pp. 278-300). Vol. 11. San Juan de Pasto: Alcaldía Municipal de Pasto.

Archila, M. (2003). Idas y venidas, vueltas y revueltas: Protestas sociales en Colombia, 1958-1990. Bogotá: Instituto Colombiano de Antropología e Historia, Centro de Investigación y Educación Popular.

Bejarano, J. A. (1983). Campesinado, luchas agrarias e historia social: Notas para un balance historiográfico. Anuario colombiano de historia social y de la cultura, (11), 251304.

Benítez, R. M. (2005). La Reforma agraria en Colombia:Vigente y por hacer. Economía Colombiana, (309).

Bonilla, R. (2011). Apertura y reprimarización de la economía colombiana: Un paraíso a corto plazo. Nueva Sociedad, (231), 46-65.

BüsCHGES, C. (2018). 50 años de la Teología de la Liberación: Introducción. Iberoamericana, 18 (68), 7-11.

Cadena, M. De LA (2015). Earth Beings: Ecologies of Practice across Andean Worlds. Durham: Duke University Press. (The Lewis Henry Morgan Lectures, 2011).

Castillo, J. \& Moreno, L. G. (1987). La variedad Colombia: Selección de un cultivar compuesto resistente a la roya del cafeto. Chinchiná: Cenicafé. 
Cely, N. (2018). La disputa por el territorio en el posconflicto rural en Colombia: El caso del Territorio Campesino Agroalimentario del Norte de Nariño y el Sur del Cauca. Análisis Político, 31 (92), 52-68.

Centro Nacional de Memoria Histórica (2013). La política de reforma agraria y tierras en Colombia: Esbozo de una memoria institucional. $1 .^{a}$ ed. Bogotá: Centro Nacional de Memoria Histórica.

Constitución Politica de Colombia (1991). Bogotá: Legis.

Coordinador Nacional Agrario (CNA) (2015). Territorios agroalimentarios: Producción, naturaleza, cultura y política campesina. Bogotá: CNA/Cedins. https://cnagrario.files.wordpress.com/2015/10/libro-territorios-agroalimentarios-1.pdf

CORRALES, E. \& Forero, J. (1992). La economía campesina y la sociedad rural en el modelo neoliberal de desarrollo. Cuadernos de Agroindustria y Economía Rural, (29), 5571.

DANE (2005). Boletín: Censo General 2005 Bogotá. https://www.dane.gov.co/ files/censo2005/PERFIL_PDF_CG2005/ 11001T7T000.PDF

Departamento Nacional de Planeación (DNP) (2019). Bases del Plan Nacional de Desarrollo 2018-2022: Pacto por Colombia, pacto por la equidad. https:/colaboracion.dnp.gov.co/CDT/Prensa/PND-2018-2022-Interactivo.pdf

Díaz FariÑas, L. (2013). A cincuenta años de la Alianza para el Progreso: El debate por el socialismo. Economía y Desarrollo, 149 (1), 139-157.

DíAz SolER, C. J. (1999). La campaña de Cultura Aldeana (1934-1936) en la historiografía de la educación colombiana. Revista Colombiana de Educación, (38-39).

DuArte, C. A. (2015). Desencuentros territoriales. 1. ${ }^{a}$ ed. Bogotá: Instituto Colombiano de Antropología e Historia.

ECHeverry, A. J. (2017). Teología de la liberación en Colombia: Un problema de continuidades en la tradición evangélica de opción por los pobres. Cali: Universidad del Valle.

EstradA, F. (2011). Por los senderos del café: La bebida del diablo: Historia económica y política del café en Colombia. Credencial Historia, (261).

FAJARDO, D. A. (2001). La tierra y el poder político: La reforma agraria y la reforma rural en Colombia. Seminario permanente sobre problemas agrarios y rurales: Proyecto «Viabilidad y reconstrucción de la sociedad rural colombiana». Bogotá, diciembre.

FAJARDO, D. A. (2012). Colombia: Dos décadas en los movimientos agrarios. Cahiers des Amériques latines, (71), 145-168.

FAJARDO, D. A. (2014). Las guerras de la agricultura colombiana 1980-2010. Bogotá: Instituto Latinoamericano para una Sociedad y un Derecho Alternativos.

Gobernación DE NARIÑo (2008). Plan de desarrollo Nariño 2008-2012. San Juan de Pasto: Gobernación de Nariño. 
Gobernación de NARIÑo (2016). Plan de Desarrollo Nariño Corazón del Mundo 2016-2019. San Juan de Pasto: Gobernación de Nariño.

Gobierno Nacional de Colombia, FARC-EPy países garantes (2016). Acuerdo final para la terminación del conflicto y la construcción de una paz estable y duradera. La Habana, 24 de agosto.

GonzÁlez, F. E. (2014). Poder y violencia en Colombia. Bogotá: Centro de Investigación y Educación Popular.

González, F. E., Bolívar, I. J. \& VÁzquez, T. (Eds.) (2002). Violencia política en Colombia: De la nación fragmentada a la construcción del Estado. Bogotá: Centro de Investigación y Educación Popular. https://issuu.com/cinepppp/docs/violencia_politica_colombia_indice_resena

GuHL, A. (2008). Café y cambio de paisaje en Colombia, 1970-2005. 1. a ed. Medellín: Fondo Editorial Universidad EAFIT/Banco de la República.

GuİZA, D. I. \& ToRRES, N. (2018). El campesinado presenta propuestas al Plan Nacional de Desarrollo. El Espectador, 21 de diciembre. https://www.elespectador.com/ economia/el-campesinado-presenta-propuestas-al-plan-nacional-de-desarrollo-articulo830482

Joseph, G. M., Nugent, D. \& Vargas, R. (Eds.) (2002). Aspectos cotidianos de la formación del estado: La revolución y la negociación del mando en el México moderno. México, DF: Era.

LeGrand, C. (1994). El agro y la cuestión social. Santafé de Bogotá:Tercer Mundo.

LEWIN, J. E. \&VÉLEZ, J. (2019). Con sus objeciones a la JEP, Duque muestra un uribismo más duro. La silla vacía, 11 de marzo. https:/lasillavacia.com/con-sus-objeciones-lajep-duque-muestra-un-uribismo-mas-duro-70428

Machado, A. (1999). Reforma agraria: Una ilusión que resultó un fracaso. Credencial Historia, (119).

Ministerio de Agricultura y Desarrollo Rural (2012). Proyecto de Ley de Tierras y Desarrollo Rural. http://www2.congreso.gob.pe/sicr/cendocbib/con4_uibd.nsf/EABE 20872C0EB09B05257B8800760D0C/\$FILE/Proyecto_Ley_Tierras_Desarrollo_ Rural.pdf

MojicA, J. (2019). Colombia, país rural sin plan de desarrollo rural. La silla vacía, 12 de marzo. https:/lasillavacia.com/silla-llena/red-rural/historia/colombia-pais-rural-sinplan-de-desarrollo-rural-70462

MontaÑA,V. (2016). Etnogénesis, desindigenización y campesinismos: Apuntes para una reflexión teórica del cambio cultural y las relaciones interculturales del pasado. Revista Colombiana de Antropología, 52 (1), 63-90.

Montenegro-Lancheros, H. (2016). Ampliaciones y quiebres del reconocimiento político del campesinado colombiano. Revista Colombiana de Antropología, 52 (1), 169195. 
Narváez Ramírez, G. (2016). Historia esencial del departamento de Nariño. Pasto: G. Narváez Ramírez. https://issuu.com/cyclops/docs/historia_escencial_de_nar_v1

Navarro, S., Pulgarín, B., Monsalve, M. L., Cortés, G. P., Calvache, M. L., Pardo, N. \& Murcia, H. (2009). Geología e historia eruptiva del complejo volcánico doña Juana (CVDJ) Nariño. Boletín de Geología, 31 (2), 109-118.

ORDóÑEz Gómez, F. (2012). Zonas de reserva campesina: Elementos introductorios y de debate. Bogotá: Instituto para una Sociedad y un Derecho Alternativos.

Oviedo, R. (2014). Sociedad, espacio y territorio: Proceso de ocupación de territorio en el Departamento de Nariño, siglos XVI-XX. San Juan de Pasto: Universidad de Nariño. Palacios, M. (2009). El café en Colombia (1850-1970): Una historia económica, social y política. 4. ${ }^{\mathrm{a}}$ ed. México, DF: El Colegio de México.

PÉREZ, P. (2007). Las zonas de reserva campesina (ZRC) en Colombia. Revista faveriana, (738), 68-77.

PÉrez Prieto, V. (2016). Los orígenes de la teología de la liberación en Colombia: Richard Shaul, Camilo Torres, Rafael Ávila, «Golconda», Sacerdotes para América Latina, Cristianos por el Socialismo y comunidades eclesiales de base. Cuestiones Teológicas, 43 (99), 73-108.

RAmírez, M. C. (2009). El Plan Colombia y la promoción de la Seguridad y el «Buen Gobierno»: ¿Militarización del contrato social como estrategia para afianzar la democracia? XXVIII Congreso Internacional de LASA, Rio de Janeiro.

REYES, A. (2016). Guerreros y campesinos: Despojo y restitución de tierras en Colombia. Bogotá: Ariel.

Rico, T. (2013). Ser y hacer, «disoñar» un proceso social: Un estudio de caso sobre campesinos narinenses. Saarbrucken: Editorial Académica Española.

Rico, T. (2016). Conocimiento, campesinos y paisajes de montaña: Relaciones entre humanos, no-humanos y espacio en la configuración de agriculturas campesinas del café en El Carmen, San Lorenzo, Nariño, Colombia. Tesis de maestría. Michoacán: El Colegio de Michoacán.

SALCEDO, L. (2013). El paro nacional agrario: Un análisis de los actores agrarios y los procesos organizativos del campesinado colombiano. https://es.slideshare.net/delDespojoCrnicas/ el-paro-nacionalagrariounanalisisdelosactoresagrariosy losprocesosorganizativosdelcampesinadocolombiano centrodeestudiosinterculturales

SAlgado, C. (2012). Proyecto de ley de tierras y desarrollo rural: ¿Cómo incorpora al campesinado? En A. MACHADO (Ed.), Propuestas, visiones y análisis sobre la política de desarrollo rural en Colombia:Voces de académicos y expertos (pp. 87-100). Bogotá: Oxfam.

SANTAColoma, L. E. (2015). Importancia de la economía campesina en los contextos contemporáneos: Una mirada al caso colombiano. Entramado, 11 (2), 38-50. 
Singh, N. (2017). Becoming a Commoner: The Commons as Sites for Affective SocioNature Encounters and Co-Becomings. Ephemera Theory $\mathcal{E}$ Politics in Organization, 17 (4), 751-776.

Toledo, A., Niño, A., Vecino, S., Buriticá, C., Díaz, D. \& Bueno, L. (Eds.) (1978). Concentraciones de desarrollo rural-CDR: Un caso de transferencia. Revista Colombiana de Educación, 1 (1).

Vega, R. (2002). Gente muy rebelde: Protesta popular y modernización capitalista en Colombia (1909-1929). Bogotá: Pensamiento Crítico.

VeGA, R. (2004). Las luchas agrarias en Colombia en la década de 1920. Cuadernos de Desarrollo Rural, (52), 9-47.

VEGA, R. (2015). La dimensión internacional del conflicto armado y social en Colombia: Injerencia de los Estados Unidos, contrainsurgencia y terrorismo de Estado. En Comisión Histórica DEL Conflicto y sus Víctimas (Ed.), Contribución al entendimiento del conflicto armado en Colombia (pp. 697-761). Bogotá: Ediciones Desde Abajo.

Wartmann, F. \& Purves, R. (2016). From Space to Place in the Bolivian Amazon: Exploring and Representing Folk Landscape Categories with Ethnographic and GIS Approaches. Oberengstringen: Claudia Wartmann Natürlich.

YIE, S. M. (2016). Demarcando el territorio de lo campesino: Dilemas de una categoría híbrida e inestable. XIII Coloquio Nacional de Sociología, Universidad del Valle, Cali, 7-10 de septiembre.

YIE, S. M. (2017). Disputando el sentido de lo campesino desde las organizaciones campesinas de Nariño, en el suroccidente de Colombia. Congreso de la Asociación de Estudios Latinoamericanos (LASA), Lima.

YIE, S. M. (2009). Los nuevos rostros del Libertador: La batalla de Bomboná en las narrativas campesinas y oficiales sobre la reforma agraria en Nariño. Anuario colombiano de historia social y de la cultura, 36 (1), 191-226.

ZalameA, J. (1936). El departamento de Nariño: Esquema para una interpretación sociológica: Estudio de la Comisión de Cultura Aldeana. Bogotá: Impr. Nacional. 